ISSN 0258-7122

Bangladesh J. Agril. Res. 37(1): 1-8, March 2012

\title{
AGRO-MORPHOLOGICAL CHARACTERIZATION AND ASSESSMENT OF VARIABILITY IN AROMATIC RICE GERMPLASM
}

\author{
M. PARIKH ${ }^{1}$, N. K. MOTIRAMANI ${ }^{2}$, N.K. RASTOGI ${ }^{3}$ AND B. SHARMA ${ }^{4}$
}

\begin{abstract}
The present studies were carried out to characterize seventy-one aromatic rice germplasm from IGKV, Raipur. These germplasm were characterized and grouped on the basis of anthocyanin pigmentation, plant habit, and awning character. On the basis of pigmentation distribution in 10 plant parts, a total of twelve groups were formed with group one having no pigmentation and group twelve with pigmentation in 9 plant parts. On the basis of plant habit and awning character, three groups of each were formed. The genetic parameters for the ten agronomic traits indicated that the selection of genotypes may be done for fertile spikelets per panicle, spikelet density, spikelet sterility percentage, and hundred seed weight. Thus, on the basis of above characters, the genotypes Tulsi Mala, Baanspati, Ganga Balu, Samund Chini, Tulsi Amrit, Dudh Dhan, Kari Gilas, Shankar Jeera, and Jata Shankar may be selected for future study.
\end{abstract}

Keywords: Rice germplasm, characterization, genetic variability.

\section{Introduction}

Rice is the world's most important food crop and a primary food source for more than one third of world's population (Singh and Singh, 2008). India is endowed with a great diversity of rice germplasm in its vast territorial land area with a variety of short, slender aromatic rice varieties which are popular in different traditional rice growing pockets. A variety of special quality rices are of great significance which deserves better premium in the domestic as well as export market. Bringing such varieties to the knowledge of consumers abroad would certainly find small but assured market for them (Siddiq, 2002). However, meager attempts have been made for the improvement of such rice genotypes. The aromatic land races possess immense potential of most valuable genes which can be effectively utilized in the present day breeding programme to evolve varieties that possess not only high yield potential and quality but also resistant to biotic and abiotic stresses. Systematic study and characterization of such germplasm is not only important for utilizing the appropriate attribute based donors, but also essential in the present era for protecting the unique rice. Thus, there is a need to collect, exploit, and evaluate the untapped germplasm.

1,2,3\&4 Department of Genetics and Plant Breeding, College of Agriculture, Indira Gandhi Krishi Vishwavidhalaya, Raipur (Chhattisgarh)-492.006, India. 
In this context, an attempt was made to characterize a set of aromatic rice germplasm for different morpholoical and agronomic traits and identify the variability available in the collection.

\section{Materials and Method}

The material for the present investigations consisted of seventy one native land race type cultivars and some of which are under by tribal community of Madhya Pradesh and Chhattisgarh region. The material was grown in a complete randomized block design with five checks in two replications during Kharif 2007. Each entry was sown in three rows of $2 \mathrm{~m}$ length at spacing of $20 \mathrm{~cm}$ between rows and $15 \mathrm{~cm}$ between plants. Observations were recorded on five randomly chosen plants of each genotype per replication for twenty-two morphological and agronomical traits. The traits studied were basal leaf sheath colour, leaf blade colour, leaf tip colour, leaf margin colour. collar colour, ligule colour, auricle colour, plant habit, apiculus colour, stigma colour, sterile glume colour, awning, plant height, panicle length, ear bearing tillers, fertile spikelets per panicle, spikelet density, spikelet sterility percentage, hundred seed weight, head rice recovery, harvest index, and grain yield per plant. The germplasm were characterized using morpho-agronornic descriptors (IRRI, 1996). Frequency distributions for all the morphological traits were computed. Statistical analysis was done for 10 quantitative traits to estimate the genetic parameters. Genotypic and phenotypic coefficients of variability were calculated following method of Burton (1952). Broad sense heritability and genetic advance were estimated as suggested by Johnson et al. (1955).

\section{Results and Discussion}

The aromatic rice genotypes under study showed wide range of variability for all the morpho-agronomical traits studied. Twelve morphological characters were recorded for seventy-one accessions. The frequency distribution for twelve morphological characters (discontinuous variables) is presented in Table I and its graphical representation is shown in Fig. 1. Out of twelve morphological characters, basal leaf sheath colour, leaf blade colour, ligule colour, plant habit, apicutus colour, and awning showed variation among the genotypes and the rest 6 was found in two classes of different genotypes. A majority of genotypes were found to possess green basal leaf sheath colour (84.5\%), green leaf blade colour (86.8\%), green tip colour (57.8\%), green leaf margin colour (57.8\%), green collar colour (97.3\%), white ligule colour (94.7\%), light green auricle colour (97.3\%), white apiculus colour (53.9\%), white stigma colour (94,7\%), and white sterile glume colour (59.2\%). Plant habit included erect (36.5\%), semi erect (44.7\%), and spreading (19.7\%). On the basis of awning character, most of the genotypes were found to be awnless (72.3\%) followed by awned (25\%) and tipped awn (2.6\%). 
Figure 1. Frequency distribution of important morphological characters.
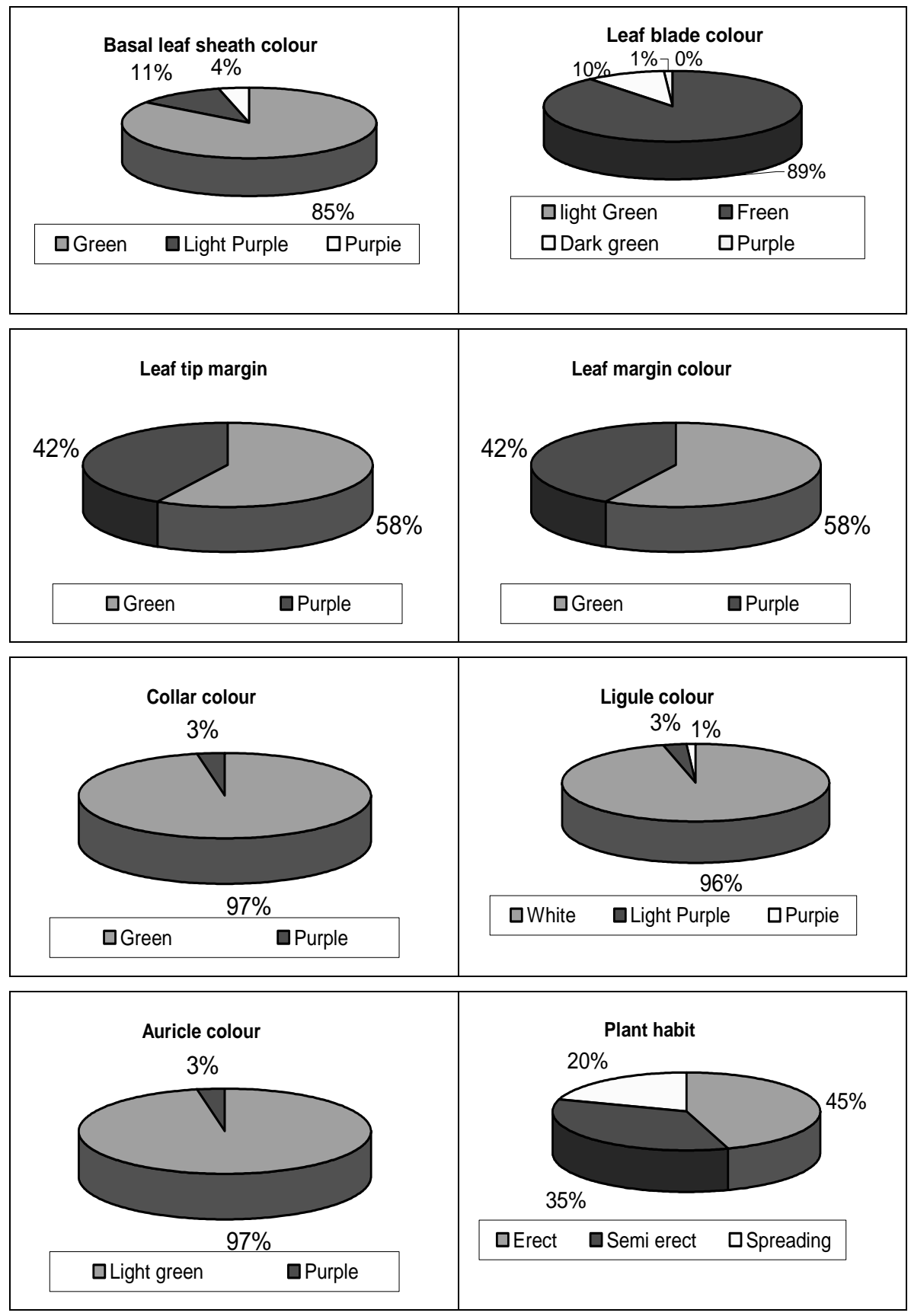
Fig. 1. Cont'd.

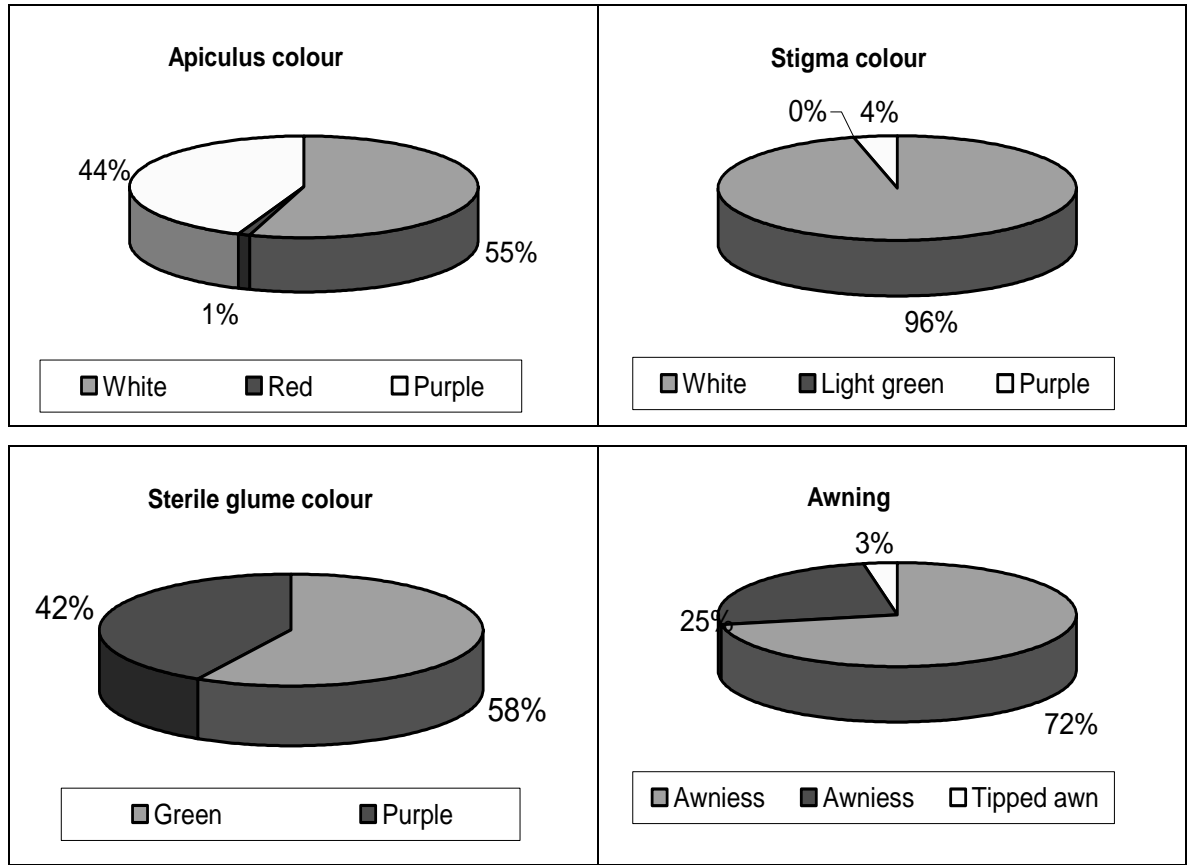

On the basis of pigment distribution in 10 plant parts, the entire germplasm was classified into twelve groups, with group I having no pigmentation and group X11 with pigmentation in nine plant parts (Table 2).

The analysis of variance revealed highly significant differences among the genotypes for all the observed characters indicating the existence of high variability among the varieties. Thus, there is an ample scope for selection of different quantitative characters for rice improvement. A perusal of GCV revealed that maximum value of variation was recorded for spikelet sterility percentage (48.55\%) followed by hundred seed weight (28.56\%), fertile spikelet per panicle (26.74\%), spikelet density (25.11\%), and grain yield per plant (22.00\%). The fertile spikelets per panicle (29.47) exhibited maximum phenotypic coefficient of variation (PCV) followed by spikelet density (28.91) and hundred seed weight (28.9 1). These results were in confirmation to the findings of Rather et al., 1998 an Pandey and John Anurag, 2010 (Table 3).

Higher estimates of PCV and GCV indicated the presence of high amount of variance and the role of the environment on the expression of these traits. The magnitude of PCV was higher than the GCV for all the characters which may be due to higher degree of interaction of genotypes with the environment (Kavitha \& Reddy, 2002). 
Table 1. Frequency distribution for agro-morphological characters in rice germplasm.

\begin{tabular}{|c|c|c|c|c|}
\hline S.No. & $\begin{array}{c}\text { Agro-morphological } \\
\text { characters }\end{array}$ & $\begin{array}{c}\text { Colour } \\
\text { pattern/ type }\end{array}$ & Frequency & Percent \\
\hline \multirow[t]{3}{*}{1} & Basal leaf sheath colour & Green & 65 & 84.5 \\
\hline & (BLSC) & Light Purple & 8 & 11.3 \\
\hline & & Purple & 3 & 4.2 \\
\hline \multirow[t]{4}{*}{2} & Leaf blade colour (LBC) & Light Green & - & - \\
\hline & & Green & 62 & 87.3 \\
\hline & & Dark Green & 8 & 11.3 \\
\hline & & Purple & 1 & 1.4 \\
\hline \multirow[t]{2}{*}{3} & Leaf tip colour (LTC) & Green & 41 & 57.7 \\
\hline & & Purple & 30 & 42.3 \\
\hline \multirow[t]{2}{*}{4} & Leaf margin colour (LMC) & Green & 41 & 57.7 \\
\hline & & Purple & 30 & 42.3 \\
\hline \multirow[t]{2}{*}{5} & Collar colour (CC) & Green & 69 & 97.2 \\
\hline & & Purple & 2 & 2.8 \\
\hline \multirow[t]{3}{*}{6} & Ligule colour (LC) & White & 68 & 95.8 \\
\hline & & Light Purple & .2 & 2.8 \\
\hline & & Purple & 1 & 1.4 \\
\hline \multirow[t]{2}{*}{7} & Auricle colour (AC) & Light Green & 69 & 97.2 \\
\hline & & Purple & 2 & 2.8 \\
\hline \multirow[t]{3}{*}{8} & Plant habit (PH) & Erect & 32 & 45.1 \\
\hline & & Semi erect & 25 & 35.2 \\
\hline & & Spreading & 14 & 19.7 \\
\hline \multirow[t]{3}{*}{9} & Apiculus colour (APC) & White & 39 & 54.9 \\
\hline & & Red & 1 & 1.4 \\
\hline & & Purple & 31 & 43.6 \\
\hline \multirow[t]{3}{*}{10} & Stigma colour (SC) & White & 68 & 96.0 \\
\hline & & Light Green & - & - \\
\hline & & Purple & 3 & 4.0 \\
\hline \multirow[t]{2}{*}{11} & Sterile -glume colour (SGC) & White & 41 & 57.7 \\
\hline & & Purple & 30 & 42.3 \\
\hline \multirow[t]{3}{*}{12} & Awning(AN) & Awnless & 51 & 71.8 \\
\hline & & Awn & 18 & 25.4 \\
\hline & & Tipped Awn & 2 & 2.8 \\
\hline
\end{tabular}


Table 2. Frequency distribution of rice germplasm accessions in respect of pigmentation in plant parts.

\begin{tabular}{|l|l|l|l|l|l|l|l|l|l|l|l|}
\hline Group & BLSC & LBC & LTC & LMC & CC & LC & AC & APC & SC & SGC & $\begin{array}{c}\text { Total } \\
\text { no. of } \\
\text { entries }\end{array}$ \\
\hline 1 & - & - & - & - & - & - & - & - & - & - & 35 \\
\hline 2 & - & - & - & - & - & - & - & + & - & - & 1 \\
\hline 3 & - & - & - & - & - & - & - & + & - & + & 3 \\
\hline 4 & + & - & + & + & - & - & - & + & - & - & 1 \\
\hline 5 & + & - & + & + & - & + & - & + & + & - & 1 \\
\hline 6 & + & - & + & + & - & - & - & + & & + & 4 \\
\hline 7 & + & - & + & + & - & - & - & + & + & + & 2 \\
\hline 8 & + & - & + & + & + & + & + & + & + & + & 1 \\
\hline 9 & - & - & + & + & - & - & - & + & - & + & 20 \\
\hline 10 & + & - & + & + & - & - & - & + & - & + & 1 \\
\hline 11 & + & - & + & + & - & + & - & + & + & - & 1 \\
\hline 12 & + & + & + & + & + & + & + & + & & + & 1 \\
\hline
\end{tabular}

+ Pigmenmted , - Non-pigmented

Basal leaf sheath colour (BLSC)

Leaf blade colour (LBC)

Collar colour (CC)

Plant habit (PH)

Auricle colour (AC)

Stigma colour (SC)
Sterile glume colour (SGC)
Leaf tip colour (LTC)

Ligule colour (LC)

Apiculus colour (APC)

Awning, (AN)

These values alone are not helpful in determining the heritable portion of variation. The proportion of genetic variability which is transmitted from parents to offspring is reflected by heritability. In the present study, high broad sense heritability was for traits like plant height $(98.00 \%)$, hundred seed weight (97.60\%), and fertile spikelets per panicle (82.30\%), while lowest heritability was observed in ear bearing tillers (42.10\%) (Table 3).

Genetic advance measures the difference between the mean genotypic values of selected population and the original population from which they were selected. The highest genetic advance was recorded for hundred seed weight (58.15) followed by fertile spikelets per panicle (49.98), spikelet density (44.88), and grain yield per plant (39.73), while lowest genetic advance was observed in head rice recovery (9.22). 
Table 3. Estimates of genetic parameters for $\mathbf{1 0}$ quantitative traits in rice germplasm.

\begin{tabular}{l|l|l|l|r|r|c|c}
\hline $\begin{array}{r}\text { S. } \\
\text { No }\end{array}$ & \multicolumn{1}{c|}{ Characters } & \multicolumn{1}{c}{ Mean } & \multicolumn{1}{c}{ Range } & GCV & PCV & $\begin{array}{c}\text { Heritability h } \\
\text { (bs) }\end{array}$ & $\begin{array}{c}\text { Genetic advance as } \\
\text { percent of mean }\end{array}$ \\
\hline 1 & Plant height & 108.70 & $42.80-146.05$ & 15.28 & 15.44 & 98.00 & 31.15 \\
2 & Panicle length & 22.56 & $16.65-26.90$ & 11.15 & 12.51 & 79.50 & 20.47 \\
3 & Ear bearing tillers & 7.32 & $4.50-10.50$ & 13.00 & 20.05 & 42.10 & 17.34 \\
4 & Fertile spikelets/panicle & 131.27 & $73.00-215.50$ & 26.74 & 29.47 & 82.30 & 49.98 \\
5 & Spikelet density & 6.84 & $3.90-11.73$ & 25.11 & 28.91 & 75.40 & 44.88 \\
6 & Spikelet sterility \% & 14.08 & $3.81-38.11$ & 48.55 & 55.47 & 76.60 & 37.57 \\
7 & Hundred seed wt & 1.41 & $0.88-2.99$ & 28.56 & 28.91 & 97.60 & 58.15 \\
8 & Head rice recovery & 65.47 & $51.39-73.70$ & 6.03 & 8.11 & 55.20 & 9.22 \\
9 & Harvest index & 44.89 & $29.92-57.47$ & 12.76 & 15.88 & 64.60 & 21.11 \\
10 & Grain yield/plant & 17.49 & $8.33-26.75$ & 22.00 & 25.12 & 76.70 & 39.73 \\
\hline
\end{tabular}


A character exhibiting high heritability may not necessarily give high genetic advance. Johnson et al. (1955) have showed that high heritability should be accompanied by high genetic advance to arrive at a more reliable conclusion. Therefore, it should be combined with information on genetic advance. Thus, a character possessing high heritability along with high genetic advance will be valuable in the selection programme. High heritability coupled with high genetic advance recorded for hundred seed weight, fertile spikelets per panicle, spikelet sterility percentage, spikelet density, and grain yield per plant, suggesting preponderance of additive gene action in the expression of these characters. Therefore, selection may be effective through these characters in segregating generation. The characters like plant height, panicle length, and harvest index exhibited high heritability coupled with moderate to low genetic advance, suggesting preponderance of non-additive gene action in the inheritance of these characters, hence, in this case selection may not be effective. Most of the above results in respect of heritability and genetic advance were in agreement with reports on rice by Sarawgi and Rastogi (2000), Vange (2009), and Pandey and John Anurag (2010).

It may be concluded that on the basis of mean performance, Tulsi Mala, Baanspati, and Ganga Balu for fertile spikelets per panicle; Samund Chini and Tulsi Mala for spikelet density; Tulsi Amrit, Baanspati, and Dudh Dhan for low spikelet sterility percentage, and Kari Gilas, Shankar Jeera and Jata Shankar for hundred seed weight were found best genotypes proving their potential for selection.

\section{References}

Burton G.W. 1952. Quantitative inheritance in grasses. In proceedings of $6^{\text {th }}$ International Grassland Congress Ames, Iowa, USA pp 227-283.

IRRI. 1996. Standard Evaluation for Rice. International Rice Research Institute, Manila, Philippines.

Johnson H.W., H.F. Robinson and R.E. Comstock. 1955. Estimates of genetic and environment variability in soyabean. Agron. J. 47: 314-318.

Kavitha S. and S.R. Reddy. 2002. Variability, heritability and genetic advance of some important traits in rice (Oryza sativa L.). The Andhra Agriculture Journal 49 (3-4): 222-224.

Pandey Praveen and P. John Anurag. 2010. Estimation of genetic parameters in indigenous rice. Advances in Agriculture and Botanics 2 (1): 79-83.

Rather A.G., G.N. Mir and F.A. Sheikh. 1998. Genetic parameters for some quantitative traits in rice. Adv. Plant Sci. 11(2): 163-166

Sarawgi A.K. and N.K. Rastogi. 2000. Genetic diversity in traditional aromatic rice accession from Madhya Pradesh. Indian J. Plant Genet. Res. 13: 138-146.

Siddiq E. A. 2002. Exploiting means to adapt GM rice. The Hindu Survey of Indian Agriculture. Kasturi and Sons Ltd., Chennai pp. 47-52.

Singh Y. and U.S. Singh. 2008. Genetic diversity analysis in aromatic rice germplasm using agro- morphological traits. J. Pl. Genet. Resour. 21(1): 32-37.

Vange T. 2009. Biometrical studies on genetic diversity of some upland rice (Oryza sativa L. ) accessions. Nature and Science 7(1):21-27. 